\title{
Uptake of hepatitis B-HIV co-infection screening and management in a resource limited setting
}

\author{
Musomba Rachel ${ }^{1 *}$, Castelnuovo Barbara', Claire Murphy ${ }^{2}$, Charlene Komujuni ${ }^{1}$, Patience Nyakato ${ }^{1}$, \\ Ponsiano Ocama', Mohammed Lamorde ${ }^{1}$, Philippa Easterbrook ${ }^{3}$ and Rosalind Parkes Ratanshi ${ }^{4}$
}

\begin{abstract}
Background: WHO hepatitis B guidelines recommend testing all new HIV patients, treating them accordingly or providing immunization. At the Infectious Diseases Institute (IDI) following an audit done in 2012, only 46\% patients had been screened for hepatitis B with variable management plans therefore new internal guidelines were implemented. This study describes the uptake of hepatitis B screening and management of patients with hepatitis B and HIV con-infection after the implementation.

Methods: Data included for all HIV positive patients in care at IDI by October 2015. Data are expressed as median with interquartile range (IQR) and percentages were compared using the chi square test. Statistical analysis was performed using STATA version 13. The IDI laboratory upper limit of normal for alanine aminotransferase (ALT) and aspartate aminotransferase (ASTs) was $40 \mathrm{lU} / \mathrm{ml}$.

Results: Number of hepatitis B screening tests increased from 800 by 2012 to 1400 in 2015. By 2015 8042/8604(93.5\%) patients had been screened for hepatitis B. Overall hepatitis B positive were 359 (4.6\%). 166 (81.4\%) hepatitis B positives were switched to a tenofovir (TDF) containing regimen.

Conclusion: Our study confirms the importance of screening for hepatitis B and of using ART regimens containing tenofovir in hepatitis B co-infected patients. Whilst our program has made improvements in care still $18.6 \%$ of patients with hepatitis B were not on tenofovir regimens, $98.1 \%$ had no hepatitis B viral loads done. Clinicians should recognize the potential for hepatitis B in HIV positive patients and the importance of early diagnosis and treatment to ensure optimal management of cases and follow up.
\end{abstract}

Keywords: Hepatitis B, HIV/AIDs, Resource limited setting

\section{Background}

Chronic viral hepatitis is an increasing cause of morbidity and mortality among HIV confected persons, including those on ART, as persons with HIV continue to live longer [1-3]. The consequences of coinfection include higher rates of chronicity, less spontaneous clearance, accelerated fibrosis progression with increased risk of cirrhosis and hepatocellular carcinoma, higher liver-related mortality, and decreased treatment response [4-6]. Other challenges with coinfection include

\footnotetext{
* Correspondence: rmusomba@idi.co.ug

${ }^{1}$ Infectious Diseases Institute, Makerere University, Mulago Hospital, P.O. Box 22418, Kampala, Uganda

Full list of author information is available at the end of the article
}

cross-resistance between HIV and hepatitis B drugs, [7-9] and increased rates of hepatoxicity [10, 11].

Chronic hepatitis B virus infection affects $5-20 \%$ of the 36 million people living with HIV worldwide, and the burden of HIV- hepatitis B co-infection is greatest in low and middle income countries, particularly in subSaharan Africa. Globally it is estimated that 2.6 million are HIV- hepatitis B co-infected [12]. The World Health Organization (WHO) in an effort to prevent and control hepatitis B Infection has developed a global action framework with four strategic axes: 1) raising awareness, promoting partnerships, and mobilizing resources 2) evidence-based policy and data for action 3) prevention of transmission 4) screening, care and treatment. These 
strategies offer a global vision for the prevention and control of viral hepatitis $[13,14]$.

Uganda is highly endemic for hepatitis B infection, with a seroprevalence for hepatitis B positivity of around $10 \%$, based on a national hepatitis serosurvey in $2005[15,16]$. As with most of Sub-Saharan Africa, the majority of infection is acquired at birth or during early childhood (Franco E, 2012). In 2002, Uganda adopted a policy of providing hepatitis $B$ vaccination to all infants [17]. Uganda has also adopted the 2013 WHO guidelines [18] that recommend hepatitis B testing in all HIV infected patients, and particularly those with elevated alanine aminotransferase (ALT), with linkage to care and treatment, and vaccination if Hepatitis B negative. Additionally knowledge of Hepatitis B serostatus allows optimal selection of antiretroviral drug (ARV) regimen to one that includes tenofovir plus lamivudine or emtricitabine (TDF/3TC or FTC) to ensure additional activity against hepatitis B $[18,19]$. During the study period, the Ugandan Ministry of Health recommendations were for immediate initiation of ART for all patients with a CD4 count less than 350 cells, and less than 500 for those with hepatitis B HIV co-infection [20].

Whilst access to HIV care is becoming widely available in Sub-Saharan Africa, in diagnosis and treatment of viral hepatitis co-infection there remains a big disparity between resource rich and poor settings. Limitations such as the availability of further investigations and medication can be challenging in these settings to provide individualized care for more complex patients, such as those with co-infection [21-24].

An audit conducted in September 2012 among newly registered patients at the Infectious Diseases Institute a large urban HIV clinic in Kampala, Uganda showed a low uptake of hepatitis B screening and variable management of those diagnosed Hepatitis B positive [25]. In response; a new specialty clinic was set up with the aim of identifying and appropriately care for patients coinfected with HIV and hepatitis B.

This study describes the impact on uptake of hepatitis B testing, assesses whether new guidelines and the introduction of the hepatitis B specialty clinic increased hepatitis B screening uptake and improved clinical management.

\section{Methods}

\section{Study site and development of hepatitis B clinic services and policies}

The Infectious Diseases Institute (IDI) is an HIV center of excellence [26] located in Mulago National referral hospital in Kampala, Uganda. IDI was one of the first HIV care and treatment organizations in Uganda; the IDI clinic began providing HIV care in 2002, while free antiretroviral treatment has been provided since April 2004. In 2015 there were more than 8000 HIV infected patients in active care.

\section{Timescale of key activities relating to delivery of hepatitis B testing and treatment at IDI}

1. In 2010, routine hepatitis B testing was first introduced, followed in 2012 by establishment of a dedicated hepatitis B clinic and clinic guidelines. The new guidelines were written by a team of three doctors, the quality manager and approved by the senior Physician who is also the head of the Prevention, Care and Treatment (PCT) department. One staff training session was conducted and the guidelines were implemented starting 1st September 2012. The hepatitis B clinic is held every Friday, staffed by doctors, nurses, counselors, laboratory technician, and pharmacist.

2. IDI has an electronic patient management system (ICEA) [27] and since the new guidelines were introduced in 2012, an electronic alert on the system that reminds clinicians to request hepatitis B tests for patients who have not been screened were further developed, the reminder prompted clinicians to request for the test. Samples were tested for hepatitis B using the hepatitis B surface antigen. Those with a positive test were termed hepatitis B positive. Routine hepatitis core antigen testing was not available.

3. Since September 2012, in accordance with the new IDI clinic guidelines, all newly registered HIV patients are tested for hepatitis B surface antigen, while those already registered in care are tested during their routine clinic appointments. ART naive hepatitis B positive patients are prepared to start ART with two pre-ART counselling sessions. In hepatitis B positive patients already on a zidovudine (AZT) based ART regimens, zidovudine (AZT) is substituted for tenofovir (TDF) if the viral load is undetectable, or switched to a second line regimen containing tenofovir (TDF), if viral failure is confirmed. Free hepatitis B testing and treatment is provided, but additional investigations including hepatitis B DNA viral load and fibro scan to help stage liver disease and monitor response to treatment; ultrasonography and alpha-fetoprotein measurement to screen for hepatocellular carcinoma; and endoscopy to screen and manage varices due to hepatitis B infection related complications need to be paid for by the patient. However, these are expensive and beyond the financial means of many of our patients. 


\section{Study population and data collection}

This analysis includes all adult ( $\geq 18$ years) HIV patients in current care at IDI from January 2002 to October 2015, with censorship at lost to follow up (LFU), transfer, or death. For each patient we recorded demographic, clinical, ART status, hepatitis B status, liver function test results, clinical management decisions regarding use of tenofovir containing ART regimen, and clinical outcomes (death, LFU, transfer etc). We also describe the number of patients tested each year, and compared the clinical characteristics and outcomes between those who tested hepatitis B positive and negative.

Two audits were undertaken for this study; the first was done in September 2012 and looked at newly enrolled patients, the second was undertaken in October 2015 following the establishment of the hepatitis BHIV clinic.

\section{Statistical analysis}

We describe the number of patients tested each year and compared baseline characteristics (age, gender, WHO stage) in hepatitis B positive and negative patients and described the clinical outcomes in hepatitis B positive patients. Data are expressed as median with interquartile range (IQR) or number and percentages as appropriate for (CD4 count at hepatitis B test, ART status, current ART regimen, time in days from ART start to hepatitis B test). Proportion of hepatitis B co-infected patients already on a TDF containing ART regimen at the time of test are described. To show trends of for patients tested before and after guideline implementation, we used proportion of patients tested for hepatitis B compared to the number of patients who registered in the period. $P$ values were found using CochranArmitage test for trend. We used an IDI laboratory upper limit of normal for alanine aminotransferase (ALT) and aspartate aminotransferase (ASTs) of $40 \mathrm{IU} /$ $\mathrm{ml}$. We used the $\mathrm{t}$ test for comparison of parametric continuous variables, Wilkinson rank sum test for nonparametric variables and chi square and fisher's exact tests for categorical variables. Statistical analysis was performed using STATA version 13.

\section{Results}

In the first audit, 1753 patients were reviewed. Of these only eight hundred seven patients $(46 \%)$ received hepatitis B testing. Twenty-nine (3.6\%) of those tested were hepatitis B positive, of which 8/29 (27.6\%) were not started on ART; of note five of those had CD4 count < 500 cells $/ \mu \mathrm{L}$. Of 21 who started ART, eighteen (62.1\%) were prescribed TDF-3TC containing regimens, three (10.3\%) on ART regimens not known to have activity against hepatitis B. 19/29 (65.5\%) patients had baseline liver function tests (LFTs) checked. No patients had follow up LFTs.

During the repeat audit in October 2015, there were 8042 (93.5\%) active HIV infected patients screened for hepatitis B at IDI. Of these,2984(37.1\%) were male, with median age 31 years (IQR: 26-35), majority in WHO stage 3 and 4; 4608(57.3\%). 7416(92.2\%) were initiated on ART and were on first line ART regimen 6930 (86.2\%). There has been a marked increase in the uptake of testing per year from 611 tests in 2010, to 909 in 2012 and now 1500 in 2015. Overall, 8042 (93.5\%) of 8604 current HIV infected patients have been screened for hepatitis B with the largest number of patients being screened between 2014 and 2015. Figure 1 shows the number of hepatitis B tests done each year over the last twelve years.

The proportion of patients screened for hepatitis B compared to the number of patients newly registered in the clinic was higher after the implementation of the new guidelines (2141(79.3\%) of 2700 versus 5901 (28.4\%) of 20,774 before the guidelines $p<0.001$ ).

\section{Characteristics of HIV-infected persons with and without hepatitis B infection as of October 2015}

Table 1 shows the descriptive characteristics of 359 (4.6\%) hepatitis B positive patients compared to the 7083 hepatitis B negative.

Those who were hepatitis $B$ positive, were more likely to be male $(52.6 \%)$ versus $(36.4 \%)(P<0.0001)$ and to have a lower median CD4 count at hepatitis B test (423 cells/ $\mu \mathrm{L}$ ) (IQR 269-600) versus 483 cells/ $\mu \mathrm{L}$ (IQR 325657). In addition, hepatitis $B$ positive had been on ART for shorter period (days 74 (IQR 27, 399) vs (105 (IQR $28,596)$ days) at the time of the hepatitis B test.

There was no difference in median age at 38 (IQR) or in WHO stage 3 and 4 (61.3\%). Three hundred thirty-seven $(93.9 \%)$ of the hepatitis B positives ever used ART with a median time on ART seventy-four days from hepatitis B test (IQR 27-399). Two hundred fifty-four (75.4\%) patients started ART before the hepatitis B test date, eighty-one (24.1\%) after the test and two $(0.5 \%)$ on the day of the test. The proportion of deaths $(6.5 \%)$ was higher among the hepatitis B positives as compared to the hepatitis B negative population $(2.3 \%)$ ( $p$ value $<0.0001)$.

The median time from testing positive for hepatitis $B$ test to death was 143 days (IQR 15-242). Hepatitis B positive patients were on ART for shorter period prior to testing (days 74 (IQR 27, 399) as compared to the hepatitis B negative patients (105 (IQR 28, 596) days) at the time of the hepatitis B test. Hepatitis B positive had lower CD4 count: 423 cells/ $\mu \mathrm{L}$, (IQR: 269-600) compared to hepatitis $B$ negative patients 483 cells $/ \mu \mathrm{L}$ (IQR:325, 657), $p$ value $<0.0001$ ). 


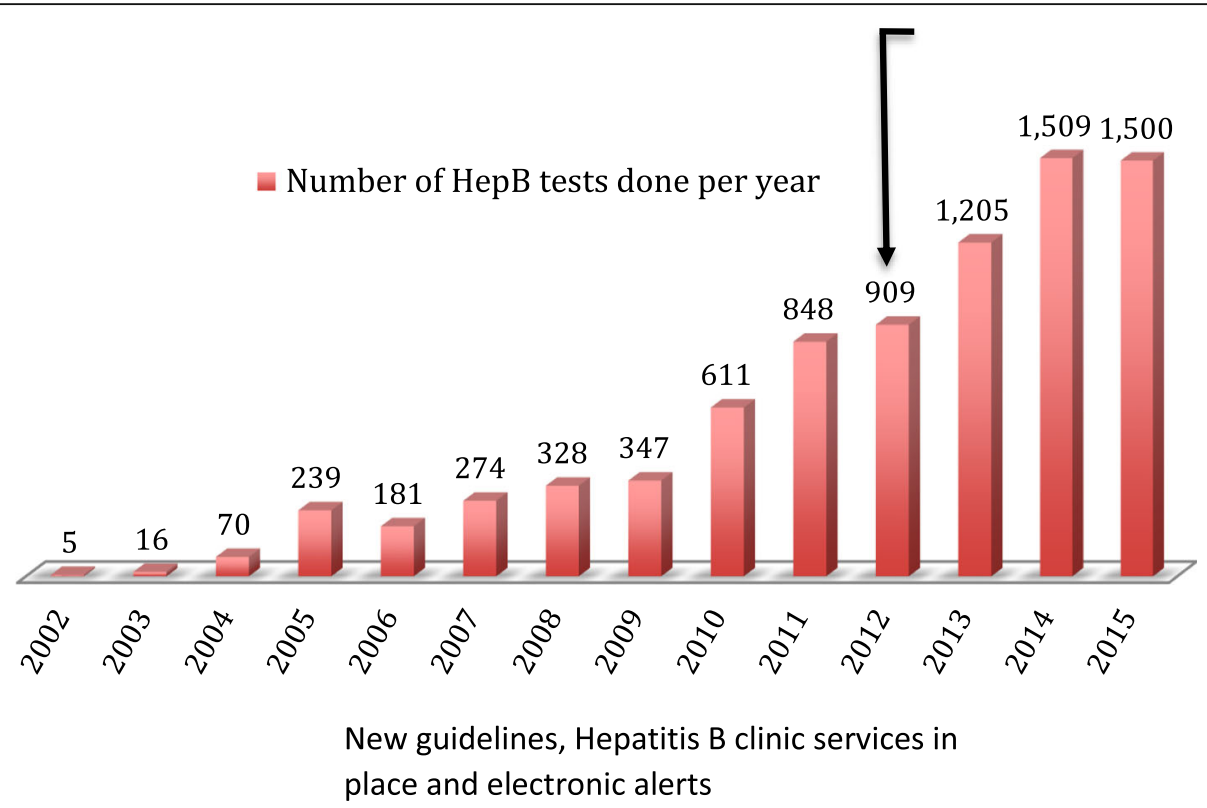

Fig. 1 Number of hepatitis B tests done performed per each year in IDI from January 2002 to October 2015

\section{Clinical management}

Figure 2. Management sequence for the 359 HIVhepatitis B positive persons, as of October 2015

\section{ART management}

337 (93.9\%) had been started on ART, while 22 (6.1\%) had not been started not on ART at the time of the analysis. Of the 22 not on ART - most died (8, 36.4\%), four (18.2\%) were lost to follow up, seven $(31.8 \%)$ had been transferred out while three (13.6\%) were active in care. One patient of those active in care had documented evidence that they refused to initiate ART while two had results returned before their scheduled return clinic appointments date. Overall 259(76.9\%) had been initiated on ART prior to their hepatitis B test, and 78 (23.105\%) after.

One hundred thirty-three of 337 (39.4\%) patients were already on a TDF containing ART regimen at the time of test, 166 of 337 (49.3\%) were subsequently switched to TDF within median of 3.7 months (IQR 1.8-6.3) from hepatitis B test, and 38 (11.2\%) were never switched. The most commonly documented reason for not switching was that the viral load was 1000 copies/ml for 24 (92.3\%) hepatitis B patients.

Table 1 Demographic and clinical characteristics among hepatitis B positive and negative patients

\begin{tabular}{|c|c|c|c|}
\hline Characteristics & Hepatitis B positive $N=359$ & Hepatitis B negative $N=7683$ & $P$ value \\
\hline Male gender $\mathrm{N}(\%)$ & $189(52.6 \%)$ & $2795(36.4 \%)$ & $<0.0001$ \\
\hline Median Age (IQR) in years & $38(32,45)$ & $39(32,46)$ & 0.119 \\
\hline WHO stage $N(\%) 3 \& 4$ & $220(61.3 \%)$ & $4388(57.1 \%)$ & 0.156 \\
\hline Median CD4 count at hepatitis B test (IQR) cells/ $\mu \mathrm{L}$ & $423(269,600)$ & $483(325,657)$ & $<0.0001$ \\
\hline Ever used ART & 337 (93.9\%) & 7079(92.1\%) & 0.231 \\
\hline \multicolumn{4}{|l|}{ Current ART regimen $\mathrm{N}(\%)$} \\
\hline First line & $316(88.0 \%)$ & $6569(85.5 \%)$ & \multirow[t]{3}{*}{0.101} \\
\hline Second line ART & $20(5.6 \%)$ & $507(6.6 \%)$ & \\
\hline Third line ART & $1(0.3 \%)$ & $1(0.01 \%)$ & \\
\hline Median time (days, IQR) from ART start to hepatitis B test & $74(27,399)$ & $105(28,596)$ & $<0.0001$ \\
\hline Active & 289 (83.2\%) & $6801(88.5 \%)$ & \multirow[t]{4}{*}{$<0.0001$} \\
\hline Dead & $23(6.5 \%)$ & 179 (2.3\%) & \\
\hline Lost & $5(1.4 \%)$ & $118(1.5 \%)$ & \\
\hline Transferred out & 33 (9.6\%) & $585(7.7 \%)$ & \\
\hline
\end{tabular}




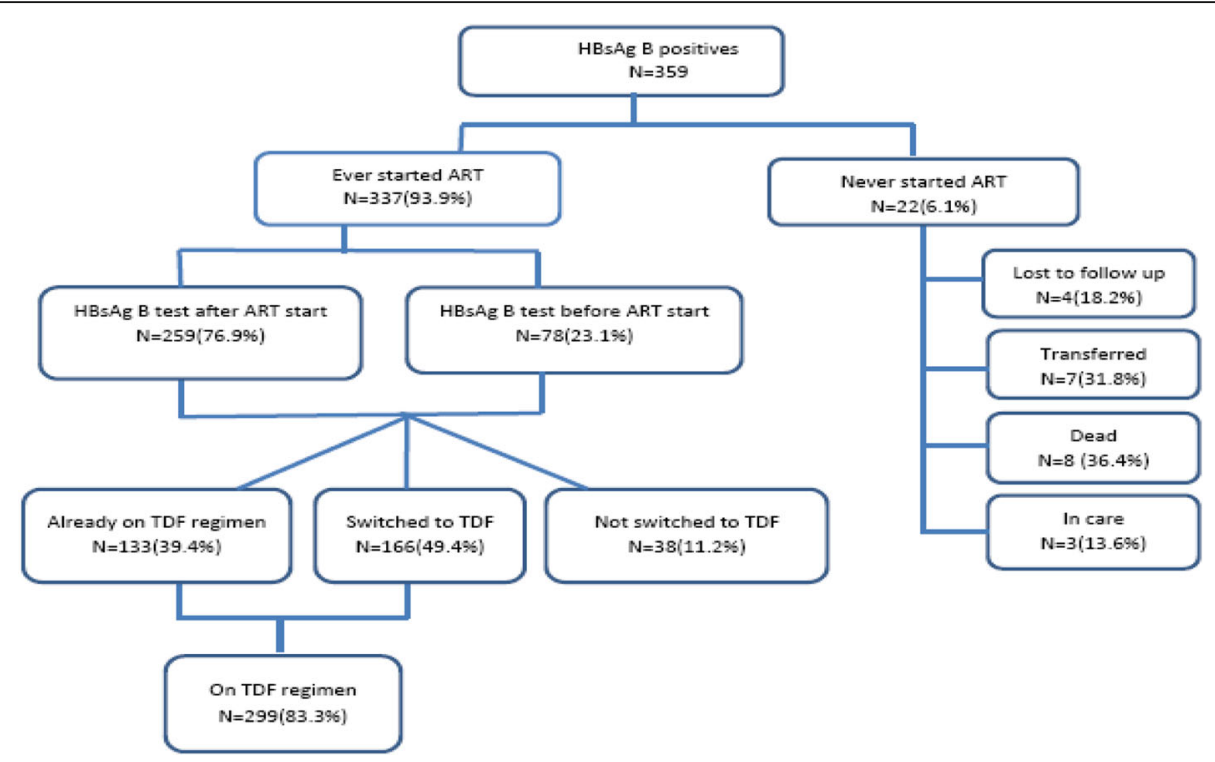

Fig. 2 Summarizes the management sequence for the 359 HIV infected persons identified as hepatitis B positive, as of October 2015

By October 2015, two hundred ninety nine (83.3\%) of 359 patients were on a TDF based regimen.

\section{Investigations and status of liver disease}

Overall 285 (79.6\%) hepatitis B positives had an HIV viral load done with $253(70.7 \%)$ of patients with viral load VL 1000 copies/ml. Patients who never had an HIV viral load done 74(20.4\%), 24 (32.9\%) patients were active in care, $17(23.4 \%)$ were dead, 4 (5.5\%) were lost from care while twenty eight $(38.4 \%)$ had been transferred out to other health care providers.

Liver enzymes tests (ALTs) were done for 249 (69.4\%) patients with 205 (82.3\%) of patients having normal alanine aminotransferase levels. Patients with Aspartate transaminase (ASTs) test done were $86(24 \%)$ most of which (61.6\%) had results in normal ranges.

Patients with hepatitis B DNA viral loads done were 7(1.9\%) while $250(69.6 \%)$ patients had an ultra sound scan done.

\section{Clinical outcomes}

Overall twenty three (6.5\%) of the hepatitis B positives died, of these $9(39 \%)$ were those who had never been initiated on ART.

\section{Discussion}

Our findings show the striking impact of the introduction and implementation of a series of clinic activities to support the provision of effective hepatitis B care in an HIV clinic. There was a progressive increase in the uptake of hepatitis B testing particularly over the preceding four years 79.3\%, with now almost universal testing of all HIV infected patients at IDI. It also shows the direct impact of knowledge of hepatitis B status on ART regimen choice with $299(83.3 \%)$ of 359 patients who were identified as positive on a TDF regimen as recommended in WHO guidelines [15] and consistent with other studies in the region [28].

This scale up and response was largely achieved as a result of results through actions taken in response to the findings of the first audit in 2012 showing a low uptake of testing [25]. These actions were the creation of a hepatitis B dedicated clinic at the facility; the development of specific guidelines; provision of, intensive training of health care worker staff on the current guidelines; and creation of a hepatitis B dedicated clinic at the facility. Further systems like the development of electronic alerts on the patient management systems (ICEA) [27] to remind clinicians to request for testing on all patients not yet tested.

Our study showed that hepatitis B occurred in $359(4.6 \%)$ patients; slightly lower than the general hepatitis B seroprevalence for Kampala regions (5.3\%) reported in the 2005 national serosurvey [16, 29, 30]. Additional reasons for the lower prevalence maybe the impact of effective ART with TDF and 3TC/FTC containing regimens which may have resulted in hepatitis $\mathrm{B}$ clearance. This concurs with other data from the multicenter AIDS cohort study showing that hepatitis $B$ was significantly lower in the ART era than in the pre-ART (IRR, 0.2 [CI, 0.1 to 0.4$]$ ), and that effective ART is associated with lower incidence of hepatitis B infection [31, 32].

Analysis of our study population showed that there were more deaths 23 (6.5\%) among the hepatitis B positives compared to the negatives patients 179 (2.3\%, $p$ 
value $<0.0001$ ). (Table 1 ) These results are similar to findings from other studies. [2, 3, 33-36].

Further investigations and management of hepatitis B patients is still a challenge. IDI has access to hepatitis B, hepatitis $\mathrm{C}$ and $\mathrm{E}$ testing only. Further investigations that would be standard in resource rich settings are not available. Additional tests including liver function tests and ultra sound scans for hepatitis B patients were not done for all the patients. Only $1.9 \%$ of patients were able to have a hepatitis B DNA viral load. In Uganda generally extensive medical investigations are expensive and beyond the financial means of IDI and many of the patients. In our settings, diagnosing chronic liver disease and hepatitis infection is currently a challenge without external funding and availability of appropriate diagnostic investigations. There are also limited drug combinations for those with drug resistance and for more complex patients, such as those with co-infection.

\section{Conclusion}

Clinicians should recognize the potential for hepatitis B in HIV positive patients and the importance of early diagnosis and treatment to ensure optimal management of cases and follow up. Effective prevention and treatment of hepatitis B virus infection is an important public health priority with effective ART being associated with lower incidence of hepatitis B infection.

The Ugandan government is making progress in prioritizing hepatitis B screening. We advocate for further budgetary allocation for the implementation of hepatitis $B$ treatment, management and long term screening for liver cancer. In the future additional funding is still required to increase management for complex patients with HIV-hepatitis B co-infection and its complications.

\section{Abbreviations \\ ART: Antiretroviral therapy; ASTs: Aspartate aminotransferase; \\ DNA: Deoxyribonucleic acid; IDI: Infectious Diseases Institute; LFTs: Liver function tests}

\section{Acknowledgements}

An abstract to this paper has been presented as a poster at ISPOR 2016 program. Poster number PHS2.

\section{Funding}

This study was self-funded.

\section{Availability of data and materials}

The Infectious Diseases Institute maintains an electronic data base where all data is stored and provided on request. All patient identifiers are removed and kept confidential.

Please you can contact author for data requests.

\section{Authors' contributions}

RM wrote the first draft of the manuscript. CM and CK conducted the first audit and were involved in the implementation of the hepatitis B clinic. PN extracted and analyzed the data. BC, PE, ML and PO reviewed the manuscript. RP overall conceived and supervised the study. All authors have reviewed and approved the manuscript.

\section{Ethics approval and consent to participate}

The protocol for the use of retrospective use of data routinely collected in IDI was reviewed and approved by the Makerere University Faculty of Medicine Research and Ethics Committee (approval number: 120-2009) and the Uganda National Council for Science and Technology (approval number: HS 683). According to the protocol procedures, patients do not provide verbal or written consent, but all their information is analyzed after removing only unique personal identifiers.

\section{Competing interests}

All authors declare that they have no competing interests.

\section{Publisher's Note}

Springer Nature remains neutral with regard to jurisdictional claims in published maps and institutional affiliations.

\section{Author details}

${ }^{1}$ Infectious Diseases Institute, Makerere University, Mulago Hospital, P.O. Box 22418, Kampala, Uganda. ${ }^{2}$ Centre for Communicable Diseases, Queen Elizabeth University Hospital, Glasgow, Scotland. ${ }^{3}$ World Health

Organizations, Geneva, Switzerland. ${ }^{4}$ Cambridge Institute of Public Health, Cambridge, UK.

Received: 19 May 2017 Accepted: 19 December 2017

Published online: 06 January 2018

\section{References}

1. Motamedifar MP, et al. The prevalence and risk factors of Hepatitis Delta virus in HIV/HBV co-infected patients in shiraz, Iran, 2012. Iran J Med Sci. 2015;40(5):448-53.

2. Soriano $\mathrm{V}$, et al. Emerging challenges in managing hepatitis B in HIV patients. Curr HIV/AIDS Rep. 2015;12(3):344-52.

3. Chen $\mathrm{G}$, et al. Chronic hepatitis $B$ virus infection and mortality from nonliver causes: results from the Haimen City cohort study. Int J Epidemiol. 2005;34(1):132-7.

4. El-Serag HB. Epidemiology of viral hepatitis and hepatocellular carcinoma. Gastroenterology. 2012;142(6):1264-73.

5. Baran B, et al. Treatment failure may lead to accelerated fibrosis progression in patients with chronic hepatitis C. J Viral Hepat. 2014;21(2):111-20.

6. Uto $\mathrm{H}$, et al. Increased rate of death related to presence of viremia among hepatitis $C$ virus antibody-positive subjects in a community-based cohort study. Hepatology. 2009;50(2):393-9.

7. Kumar R, Singla V, Kacharya S. Impact and management of hepatitis B and hepatitis C virus co-infection in HIV patients. Trop Gastroenterol. 2008;29(3): 136-47.

8. Puoti $M$, et al. Hepatitis B virus co-infection in human immunodeficiency virus-infected subjects. AIDS Rev. 2002:4(1):27-35.

9. Matthews GV, et al. Characteristics of drug resistant HBV in an international collaborative study of HIV-HBV-infected individuals on extended lamivudine therapy. AIDS. 2006;20(6):863-70.

10. Sulkowski MS, et al. Hepatotoxicity associated with antiretroviral therapy in adults infected with human immunodeficiency virus and the role of hepatitis C or B virus infection. JAMA. 2000;283(1):74-80.

11. den Brinker $M$, et al. Hepatitis $B$ and $C$ virus co-infection and the risk for hepatotoxicity of highly active antiretroviral therapy in HIV-1 infection. AIDS 2000;14(18):2895-902.

12. Prevalence and burden of HCV co-infection in people living with HIV: a global systematic review and meta-analysis. Platt L, Easterbrook P, Gower E, McDonald B, Sabin K, McGowan C, Yanny I, Razavi H, Vickerman P. Lancet Infect Dis. 2016 Jul;16(7):797-808. doi: https://doi.org/10.1016/S14733099(15)00485-5. Epub 2016 Feb 25. Review.PMID: 26922272.

13. Chen, D.S., et al., Report from a viral hepatitis policy forum on implementing the WHO framework for global action on viral hepatitis in North Asia: J Hepatol 2013 Nov;59(5):1073-1080. doi: https://doi.org/10.1016/j.jhep.2013. 06.029. Epub 2013 Jul 12

14. WHO, Prevention and Control of Viral Hepatitis Infection: Framework for Global Action. 2012: p. 28

15. Ocama $P$, et al. Hepatitis B and HIV co-infection is still treated using lamivudine-only antiretroviral therapy combination in Uganda. Afr Health Sci. 2015;15(2):328-33. 
16. Bwogi J, et al. Hepatitis B infection is highly endemic in Uganda: findings from a national serosurvey. Afr Health Sci. 2009;9(2):98-108.

17. UNEPI, Uganda National Expanded Program on immunisation. 2002. http:// www.nationalplanningcycles.org/sites/default/files/country_docs/Uganda/ uganda_epi_cmyp_2012-2016_update_2013.pdf

18. WHO, Consolidated Guidelines on the Use of Antiretroviral Drugs for Treating and Preventing HIV Infection: Recommendations for a Public Health Approach. Vol.. 2013: PMID: http://www.who.int/hiv/pub/guidelines/ arv2013/en/

19. WHO, World Health Organization (WHO) guidelines for the prevention, care and treatment of persons living with chronic hepatitis B (CHB) infection 2015.

20. MOH guidelines, The 2013 Uganda Ministry of ART Health guidelines 2013 (http://www.who.int/hiv/amds/uganda_moh_treatment_guidelines.pdf).

21. Stockdale AJ, Geretti AM, Chronic h B. Infection in sub-Saharan Africa: a grave challenge and a great hope. Trans R Soc Trop Med Hyg. 2015 Jul; 109(7):421-2. https://doi.org/10.1093/trstmh/trv044.

22. Lemoine $\mathrm{M}$, Eholie $\mathrm{S}$, Lacombe K. Reducing the neglected burden of viral hepatitis in Africa: strategies for a global approach. J Hepatol. 2015;62(2): 469-76.

23. Nwokediuko SC. Chronic hepatitis B: management challenges in resourcepoor countries. Hepat Mon. 2011:11(10):786-93.

24. Lacombe K, et al. HIV/hepatitis B virus co-infection: current challenges and new strategies. J Antimicrob Chemother. 2010;65(1):10-7.

25. Claire Murphy, E., Challenges of hepatitis B-HIV co-infection screening and management in resource limited settings. BHIVA, Abstract 2012(www.bhiva. org/documents/Conferences/.../HIVMedicine12.pdf).

26. Nwaka S, et al. Analysis of pan-African Centres of excellence in health innovation highlights opportunities and challenges for local innovation and financing in the continent. BMC Int Health Hum Rights. 2012;12(11):12-1.

27. Castelnuovo B, et al. Implementation of provider-based electronic medical records and improvement of the quality of data in a large HIV program in sub-Saharan Africa. PLoS One. 2012:7(12):17.

28. Wandeler $G$, et al. Hepatitis B infection, viral load and resistance in HIVinfected patients in Mozambique and Zambia. PLoS One. 2016;11(3)

29. Teshale $E H$, et al. Hepatitis B virus infection in northern Uganda: impact of pentavalent hepatitis B vaccination. Vaccine. 2015:29(15):01334-1.

30. Macro, M.o.H.U.a.O., Uganda HIV/AIDS Sero-behavioural Survey 2004-2005. Calverton, Maryland, USA, 2006: p. 114-116.

31. Falade-Nwulia $\mathrm{O}$, et al. Incident hepatitis $\mathrm{B}$ virus infection in HIV-infected and HIV-uninfected men who have sex with men from pre-HAART to HAART periods: a cohort study. Ann Intern Med. 2015;163(9):673-80.

32. Marcellin $\mathrm{P}$, et al. Effectiveness and safety of Tenofovir Disoproxil fumarate in chronic hepatitis B: a 3-year, prospective, real-world study in France. Dig Dis Sci. 2016;28:28

33. Nikolopoulos GK, et al. HBV-DNA levels predict overall mortality in HIV/HBV coinfected individuals. J Med Virol. 2015;19(10):24357.

34. Kim JH, Psevdos G Jr, Sharp V. Five-year review of HIV-hepatitis B virus (HBV) co-infected patients in a new York City AIDS center. J Korean Med Sci. 2012; 27(7):830-3.

35. van Meer S, et al. Hepatocellular carcinoma in cirrhotic versus noncirrhotic livers: results from a large cohort in the Netherlands. Eur J Gastroenterol Hepatol. 2015;1:1.

36. Kubo $\mathrm{S}$, et al. Management of hepatitis $B$ virus infection during treatment for hepatitis B virus-related hepatocellular carcinoma. World J Gastroenterol. 2015;21(27):8249-55

\section{Submit your next manuscript to BioMed Central and we will help you at every step:}

- We accept pre-submission inquiries

- Our selector tool helps you to find the most relevant journal

- We provide round the clock customer support

- Convenient online submission

- Thorough peer review

- Inclusion in PubMed and all major indexing services

- Maximum visibility for your research

Submit your manuscript at www.biomedcentral.com/submit

) Biomed Central 